\title{
Structural and Semantic Features of Quotation in English Media Discourse
}

\author{
Yulia Volynets \\ Senior Lecturer \\ National Research University Higher School of Economics, Moscow \\ jpvol@bk.ru
}

\section{Doi:10.5901/ajis.2013.v2n8p554}

\begin{abstract}
Quotation, being one of the most common structural and semantic constituents of media discourse, is widely employed by a great number of journalists time and again. Since it may perform various functions, quotation constitutes a powerful tool at reporters' disposal used to suit their own purposes. Consequently the analysis of this issue can be found in numerous works, but authors mostly study quotation from a stylistic perspective, paying less attention to its lexical aspect, which requires a closer examination. Thus the present research targets at the analysis of quotes' structural types and their semantic features in English media discourse, subjecting to conscious scrutiny the borrowing of a quote's form and content in the process of introducing the quoted text into a new one. For carrying out this research, quotations from the following newspapers: the New York Times, the Financial Times, the Economist, the Spectator, the Sun, The Wall Street Journal were examined according to existing classifications. The research is based on a descriptive analysis of various quote types and their specific features. Despite the fact that some statistical data are provided in this paper, the approach adopted is more observational. The findings suggest that although the quote is expected to meet the structural and semantic organization of an authentic text, in media discourse authors often break this rule for pursuing particular objectives. The study reveals that intentional changes in reported speech and the influence of a new context environment may alter the meaning of the quoted utterance. The research outcomes verify the idea that quotation, being a journalist's powerful tool, plays an important role within a text and the understanding of quotes' structural and semantic peculiarities is likely to assist readers in perceiving and analyzing information.
\end{abstract}

Keywords: English media discourse, quotation, lexical aspect, structural types, semantic features

\section{Introduction}

Quotation being an inalienable feature of media discourse is widely used by a great number of authors time and again, as it helps them to solve a set of different tasks such as to state particular facts, making information more precise and vivid, to express indirectly one's attitude towards the quoted statement, to create a dramatic effect, influencing readers, and even to detach from what is claimed.

Consequently the analysis of this issue can be found not only in works of leading theorists (e.g. Prof. Galperin, Prof. Bahtin), but also in numerous publications of modern writers, who have carried out a great amount of research into structural, semantic and pragmatic aspects of quotation.

The fact that there are a lot of questions concerning a multifaceted nature of quotation, its place, role in a text and language peculiarities explains the existence of a great number of approaches and theories dealing with this notion. The textual nature of quotation accounts for the fact that it shares many characteristics typical of an ordinary text such as its structural, informative, indicative and intertextual nature, its directedness, intentionality and pragmatic value. (Galperin, 1981, p.18)

\subsection{Approaches to studying quotation}

Thus three different approaches to studying quotation are acknowledged in modern linguistics: structural, communicative and linguo-cultural, they reflect main streams in contemporary discourse research. (Karasik, 1998, p.185)

\subsubsection{Structural approach}

The representatives of this scholarly approach (M.U. Bulah, I.R. Galperin, K.N Dairova, , O.G. Moskalskaya) pay most attention to a structural aspect of quotation, studying interrelations between a quote and the author's text, classifying 
semantic constituents of an introductory complex and identifying main semantic types of quotation.

Quotation is regarded as a means of structural and compositional text formation, providing its logical coherence and cohesion. According to Prof. Galperin, being a tool for contextual text segmentation, quotation forms one of the basic text categories- its information value. (Galperin, 1981, p.52) Moreover, this approach presupposes studying structural and semantic features of quotation in line with its functional characteristics.

\subsubsection{Communicative approach}

The supporters of this approach (V.P. Androsenko, G.S. Salova, V.E. Chernyavskaya) highlight the idea that such characteristics of quotation as information value, modality, contextual meaning are closely connected with a communicative situation the quote is produced in. It is claimed that taking into account the influence of external environment on the interrelation between a quote and a text leads to a better understanding of a quote's communicative function peculiarities.

\subsubsection{Linguo-cultural approach}

The advocates of this approach (U.M. Lotman, Z.G. Mints, D. Meyer) consider quotation as a cultural sign, the sign of a quoted culture. Quotation, being regarded from this perspective, implies the analysis of background knowledge of an addressee, the awareness of important cultural, social and historical aspects of that language and the insight in its genre and stylistic peculiarities.

However, although a great amount of research into quotation is carried out, it is worth mentioning that it is mostly based on the analysis of scientific discourse texts, thus the notion of quotation in media discourse still remains quite incomprehensive and needs closer examination. Taking as its starting point the previous research of Prof. Aleshchanova into quotation in media discourse, the present paper targets at the descriptive analysis of quotes' structural types in English media discourse, paying attention to the borrowing of a quote's form and content in the process of introducing the quoted utterance into a new text, moreover in order to account for roles a quote might play in a sentence, the semantic analysis is carried out.

\section{Quotation structural classification}

Since quotation is really popular with many authors, it is quite reasonable that there are a great number of classifications, based on different criteria or characteristics of quotes. For example, Prof. Aleshchanova in her Candidate of Science Thesis "Quotation in media discourse" among other classifications, suggests grouping quotes according to their form, thus she defines the following structural types: full, reduced and segmented quotes. (Aleshchanova, 2000)

Being under the influence of many extra- and inter-linguistic factors, which also determine quotes' semantic and pragmatic features in a new text, the structural aspect of quotation is assumed to be the most disposed to various modifications.

Based on quotes' structural peculiarities, the classification introduced in this paper is also intended to cover some questions pertaining to the correlation between a quote's content in an authentic environment and in a new one. It appears that structurally a quote can be expressed by a sentence (quote-sentence), a word combination (quote-wordcombination) and a word itself (quote-word).

Table 1.

\begin{tabular}{|c|c|c|}
\hline Quote-word & Quote-word-combination & Quote-sentence \\
\hline 53 & 447 & 658 \\
\hline
\end{tabular}

Data: Survey, December 2012

Table 1 provides statistics, which is based on the analysis of 250 articles taken from the following newspapers: the New York Times, the Financial Times, the Economist, the Spectator, the Sun and The Wall Street Journal. It illustrates that the type quote-sentence prevails in newspaper articles, which may be explained by the fact that, being quite neutral and easy to employ, this structural type allows communicating particular facts and real words of a quoted person, which makes 
information in a news report look more objective and alive.

The quote-sentence type presents a literal logically finished utterance, without any abridgements.

e.g.:

"The initiation of baby boomers going into retirement is absolutely the primary factor that has driven this shift in focus," says Michael Doshier, vice-president of retirement marketing at Franklin Templeton Investments. (The Financial Times, 'Decumulation' phase moves higher up agenda, December 7, 2012)

"They need more incentive to make the transition that they must know they need to make, from fossil fuel companies to energy companies," Mr. McKibben said. (The NY Times, To Stop Climate Change, Students Aim at College Portfolios, December 4, 2012)

The quote-word-combination type is represented by a contracted part of a quoted text, the content of which is not altered. While this quotation type is not introduced by any words, it still logically fits the new environment, becoming a part of a sentence. The case of quotation in this type is apparent only in writing as quotation marks are used.

e.g.:

To help this timescale along, PF2 will introduce "a comprehensive suite of standard documentation", the report promises.

(The Financial Times, Doubling down: PFI becomes “PF2", December 5, 2012)

Set out your "strategic posture" - for instance, emphasising IT as a driver or enabler of strategy. (The Financial Times, The first 100 days of a new CIO: Nine steps for wiring in success, December 4, 2012)

According to the findings of this study, which are constituent with what is known about quotation, the quote-word type is the least employed by authors, while it is also claimed to be the most expressive one. Quotes of this type are inseparably linked with the text they are introduced in.

e.g.:

The British state's determination to chase foreign earnings while lowering public spending threatens the judicial standards that bring in international "business" in the first place. (The Spectator, Export only justice, December 8, 2012)

Having the luxury of 41 megapixels for input and only 3, 5 or 8 megapixels needed for output, the technology takes full advantage of a technique known as "oversampling". (The Economist, Difference Engine: True to its image, December 3, 2012)

Due to their logical incompleteness and syntactic dependence on a new text, the quotes of both the wordcombination and the word type are considered to be synsemantic utterances.

\subsection{The correlation of language systems}

One of major challenges when introducing a quote into a new text is the correlation of two language systems: the system of a quoted utterance and the one of a "text-receiver". On general grounds, three basic variations of this correlation can be recognized:

First variation- the general meaning of a quote remains the same in a new text.

e.g.:

"Russia is a lot more bureaucratic than India or Brazil and you lose a lot more time in red tape than in other markets when founding a venture and dealing with logistics", he says. (The Financial Times, Eastern premise, December 3, 2012)

John Rishton, Rolls-Royce chief executive, said: "I want to make it crystal clear that neither I nor the Board will tolerate improper business conduct of any sort and will take all necessary action to ensure compliance. This is a company with exceptional prospects and I will not accept any behaviour that undermines its future success." (The Financial Times, Rolls-Royce reveals SFO corruption probe, December 6, 2012)

Eyal Gruner, a security engineer who tracked the virus at Versafe, an online security company, said: "More than 30 per cent of the EU and US banks use something similar to this mechanism." (The Financial Times, Hackers net $€ 36 \mathrm{~m}$ in Europe banking attack, December 5, 2012) 
Second variation- the general meaning of a quote remains the same but there are some changes in its expression, some of a quote's components are changed to meet a language situation of a new text.

e.g.:

Thus Parisian taxi drivers not long ago resorted to an inventive "work-to-rule" tactic after being confronted with new regulations. (The Wall Street Journal, Disordered Liberty, December 4, 2012)

Approval of the bill immediately labelled by Russia's foreign ministry as "theatre of the absurd".( The New York Times, Magnitsky bill passes on trade deal, December 6, 2012)

"The more tools that are out there, the better," he says. (The Financial Times, 'Decumulation' phase moves higher up agenda, December 7, 2012)

And the final one - the meaning of a quote in an authentic text and in a "text -receiver" is not identical. A quote's semantics (its semantic meaning and a meaning produced by a new context environment) does not meet the standards of a "text-receiver", in that case a quote is used as a kind of association or an expressive tool, for attracting readers' attention or even as a design tool, for making a piece of writing look attractive.

e.g.:

Numerous cities have set up a "happiness index" based on everything from the number of pollution particles in the air to subjective factors for measuring municipal ecstasy. (The Wall Street Journal, The folly of ranking national nirvana, December 4, 2012)

Executives in technology, retail, marketing and other industries like to say that data is "the new oil" or, at least, the fuel that powers the Internet economy. (The New York Times, A Vault for Taking Charge of Your Online Life, December 9 , 2012)

When choosing a kind of variation, authors usually target at creating a particular effect. It is a well-known fact that the quote is expected to meet the structural and semantic organization of an authentic text, the findings of the research suggest that in media discourse if authors break this rule when choosing a kind of structure and variation, they usually pursue a particular objective.

The study reveals that the first variation, which is usually structurally expressed by the type quote-sentence, is the most common one in newspaper articles due to the fact that many journalists resort to it for conveying particular facts or real words of a quoted person, which makes their piece of writing more precise and vivid. While the second variation type, being quite expressive, is more typical of newspaper headlines and used by authors to attract the readers' attention.

The third variation type along with the second one is also used for evoking readers' interest. By using quotes in the stylistic environment and a thematic context different from their initial one, journalists employ figurative language ${ }^{1}$, creating some specific effects, such as literary tropes ${ }^{2}$, which makes their writing more attention-grabbing and eyecatching.

Therefore any quotation has an additional semantic meaning, which is inherited from an initial language environment, where the quote is first produced in. (Shylezhkova, 1995, p.223) That language environment is always implicitly or explicitly reflected in a quote, introduced into a new context, creating an additional semantic meaning. According to Prof. Litvin, the understanding of that meaning may present some difficulties and requires that a person should be aware of the first language environment of a quote, where it got an additional semantic meaning. (Litvin, 1984,p.119) It is also necessary to mention that intentional changes in reported speech and the influence of a new context environment may alter the meaning of the quoted utterance.

\section{The analysis of quotation semantic features}

As it has been mentioned before, quotation is widely used by authors for completing various communicative tasks, and the practice of quoting among newspaper journalists is becoming more and more popular. The extraction of certain

\footnotetext{
${ }^{1}$ http://en.wikipedia.org/wiki/Literal_and_figurative_language
}

${ }^{2}$ https://en.wikipedia.org/wiki/Trope__(literature) 
utterances from one's speech and their introduction to a new context may have different functions, which were studied by such authors as Prof. Aleshchanova, Prof. Fairclough and linguist Nylund.

In his article on the narrative functions of quotes, Nylund concludes that quotation in today's media performs a variety of functions: by using quotes, a journalist can validate, criticize, certify, evaluate the information, or even distance oneself from what is quoted. Quotation helps to make a story more alive, captivating readers and grabbing their attention. According to Nylund, quotes add a sense of presence, emotions and subjective experience to a news report. (Nylund, 2003, pp.844-851)

In contrast to several other studies on quotation functions, which mainly dwell on pragmatic aspect of this question and build their classifications basing on the communicative meaningfulness of the quoted utterance or journalists' perspectives in employing quotes, the classification offered in this research is based on the one, given by Prof. Aleshchanova in her Candidate of Science Thesis "Quotation in media discourse", where she defines a "quote example", a "quote opinion" and a "quote substitute" type according to the functions utterances perform in a text. These functions are described as follows: a referential one, which presupposes supplementing with details the context environment, the quote is inserted in; a cognitive one, which refers to processing, learning, remembering, storing information and to expressing cultural experience of society and an informative function, which is used for carrying out particular communicative tasks in the process of communication. (Aleshchanova, 2000) This paper aims at analyzing the peculiarities of these quote types and their interconnection with other quotation characteristics observed in the article before.

The quote-opinion type represents the result of reality comprehension by a speaker and their reaction to it, and forms a basis for its further analysis by the author of an article.

e.g.:

"We think that the MBA programme is very revolutionary and offers much more hands-on practical experience in emerging markets than most MBAs," says Valeria Pavlyukovskaya, director of the school's executive MBA programme, which includes a module in which participants start up their own business. (The Financial Times, Eastern premise, December 3 , 2012)

"There is no such thing as an IT project," advises David Elton, an IT and change management specialist at PA Consulting. "There are only business projects with IT in them." This is leading, in the view of some experts, to the role of chief information officer becoming more closely allied to that of chief operating officer, and to some companies giving managers responsibility for IT alongside facilities or property management more generally. Other observers, however, believe IT remains too complex to become part of a generalist's portfolio. (The Financial Times, Spending: Cost control develops into full reviews of processes, December 4, 2012)

The quote-example type, carrying factual information, is considered as a means of explaining and proving the speaker's position. Most journalists resort to this quote type for the reason that it comprises a great amount of statistics, which makes news more objective.

e.g.:

"When people get crazy over something, they like to rationalize what they do," Mr. Kusin added. "If a Russian oligarch is going to spend $\$ 88$ million, then somehow he has to justify it. So he says it's more than an apartment. It's art. That's absolutely ridiculous. At the end of the day, it's still a piece of real estate. It's immovable, and it needs to be maintained." (The New Your Times, Overpriced Real Estate? Well, Maybe It's Art, September 1, 2012)

"If the water comes up too high onto the streets of New York it could damage our equipment, it would damage our customers' equipment and there's a lot more damage if the equipment is energized, so we might be preemptively deenergizing that equipment in advance," Mr. Burke said. (The Wall Street Journal, Parts of New York City Evacuated for Hurricane Sandy, October 28, 2012)

The quote substitute type is a contextually dependent utterance, which is structurally expressed by a reduced or segmented quote. The process of introducing quotes of this type into a text does not represent any difficulty and results in a cohesive narration. Moreover the usage of this quote type makes narration more vivid and in some cases helps authors to avoid being accused of subjective information interpretation.

e.g.:

"Climate-safe" cities, if any exist, might limit their own development when confronted by flows of migrants from vulnerable 
areas. (The Economist, Heated Debate, December 8, 2012)

America is 'browning', as Frey puts it, as a result of high immigration levels from Latin America and Asia and the fact that an older white population is having fewer children than immigrants and their children. (The Spectator, Barack Obama's new ethnic majority, November 10, 2012)

It is generally assumed that all discourses and utterances are dialogical in their nature, they all carry some meanings based upon speakers' previous usage of the same words (Bakhtin, 1986; Linell, 1998). According to CaldasCoulthard "No speech representation is objective or simply neutral". (Caldas-Coulthard, 1994,p.307) Even if a person is quoted word-for-word and an utterance is simply extracted from one context to another, a shift of meaning is still likely to take place. (Caldas-Coulthard, 1994; Linell, 1998).

Needless to say, that to quote somebody is to manage "the words of others to convey and serve the purpose of the writer, giving a slant to what is said."(Calsamiglia \& Ferrero, 2003, p.149). In media discourse, journalists actively make use of quotations, trying to "control the way readers process and make sense of the report" (Teo, 2000,p. 14). The findings of this research suggest that newspaper authors may alter the organization of a quoted utterance, trying to achieve desired effects, which in their turn usually determine the author's choice of a quote structural and semantic type.

\section{Conclusions}

Both the content of a quoted utterance and the way it is represented in a new environment play a significant role in verbal and written discourse. (Bakhtin, 1981) The process of citing presupposes that a new text somehow borrows the form and the content of a quote, where more attention is paid to a semantic aspect due to its predominance over a structural one. The findings suggest that quotation acts as a kind of mediator between two language environments: an initial language environment, where the quote is first produced, and a new environment it is introduced into.

Meeting the aim of this research, which was to analyze quotes' structural types and their semantic features in English media discourse, the paper systemizes common knowledge and provides a descriptive analysis of quotation classifications and their peculiarities. Moreover theoretical material is illustrated with real examples, which facilitates the understanding of the given information. Therefore this study provides insights into structural and semantic features of quotation and assists readers in perceiving and analyzing information given in English media discourse.

\section{References}

Aleshchanova, I.V. (2000). Quotation in Media Discourse. Candidate of Science Thesis: 10.02.20 Volgograd.

Burgo, C. (2007) Reporting verbs in Spanish and French press: Informant's or speaker's perspective?.Georgetown University LusoHispanic Linguistics Papers, 1-10.

Caldas-Coulthard, Carmen Rosa (1994), On reporting reporting: The re-presentation of speech in factual and fictional narratives. In Coulthard, Malcom (Eds.), Advances in Written Text Analysis(pp. 295- 308). London: Routledge.

Calsamiglia, H. \& Lopez Ferrero, C. (2003), Role and position of scientific voices: reported speech in the media. Discourse Studies, Vol. 5 (2). $147-173$.

Fairclough, N. (1992). Discourse and Social Change. Cambridge: Polity Press.

Fairclough, N. (1995). Media Discourse. London: Edward Arnold.

Galperin, I.R. (1981). Text as an Object of Linguistic Research. Moscow: Science.

Gibson, Rhonda, Hester, Joe B \& Stewart, Shannon (2001), Pull quotes shape reader perceptions of news stories. Newspaper Research Journal, Vol. 22 (2). 66-78.

House, D. (1990) Total Perception in Speech. Lund.

Karasik V.I. (1998). About discourse categories. Language Personality: sociolinguistic and emotive aspects (pp.185 - 197). Volgograd: Peremena.

Linell, P. (1998), Approaching Dialogue: Talk and Interaction in Dialogical Perspectives. Amsterdam: Benjamins.

Litvin, F.A. (1984). A multifaceted nature of a word in language and speech. Moscow: Higher School.

Nylund, M. (2003). Quoting in front-page journalism: illustrating, evaluating and confirming the news. Media, Culture \& Society, Vol. 25 (6). 844-851.

Schiffrin, D. (1994). Approaches to Discourse. Oxford: Blackwell Publishers.

Shylezhkova, S.G. (1995). Eloquent expressions, their sources and development. Chelyabinsk: Fakel.

Teo, P. (2000). Racism in the news: A critical discourse analysis of news reporting in two Australian newspapers. Discourse \& Society, Vol. 11 (1). 7-49. 